\title{
Analysis of Solid-State Interactions of Ketoprofen-Coformer Binary Mixtures by DSC and Hot Stage Microscopy
}

\author{
Yudi Wicaksono ${ }^{1 *}$, Dwi Setyawan², Siswandono ${ }^{3}$ \\ 'Department of Pharmaceutics, Faculty of Pharmacy, University of Jember, \\ Jember, 68121, Indonesia \\ ${ }^{2}$ Department of Pharmaceutics, Faculty of Pharmacy, Airlangga University, \\ Surabaya, 60286, Indonesia \\ ${ }^{3}$ Department of Pharmaceutical Chemistry, Faculty of Pharmacy, Airlangga University, \\ Surabaya, 60286, Indonesia
}

*Corresponding author email: yudi.farmasi@unej.ac.id

Received January 27, 2020; Accepted May 19, 2020; Available online July 27, 2020

\begin{abstract}
Ketoprofen is a non-steroidal anti-inflammatory drug with poor water solubility, so the absorption is less than optimal. One method to improve the solubility of ketoprofen is through the formation of multicomponent solid forms. The success of the formation of the multicomponent solid forms is strongly influenced by interactions between components in their solids. In this study, the analysis of the interactions in solid form of ketoprofen-coformers was carried out using the differential scanning calorimetry (DSC) and hot stage microscopy (HSM) with adipic acid and isonicotinamide as coformers. From the experimental results, the mixtures of ketoprofen-adipic acid show a solid-liquid phase diagram that indicates a simple eutectic system with eutectic points on the molar fraction of ketoprofen 0.9 and temperature at $92.9^{\circ} \mathrm{C}$. The ketoprofen-isonicotinamide mixtures have a eutectic system with the peritectic point. The solid-liquid phase diagram has indicated that the ketoprofen-adipic acid in eutectic composition forms a miscible liquid phase without interaction in its solid form, whereas the ketoprofen-isonicotinamide forms a miscible liquid phase accompanied by interaction with the excess component. The results of the HSM analysis showed the same phenomenon as the result of the DSC experiment and have confirmed with the FTIR analysis.
\end{abstract}

Keywords: Solid-state interaction, phase diagram, the eutectic composition

\section{INTRODUCTION}

The compounds can form interactions with others to produce various types of multicomponent solid forms (Shayanfar \& Jouyban, 2013; Haneef \& Chadha, 2017). New solid forms resulting from intermolecular interactions between solid compounds will have physicochemical properties that are significantly different from the starting compounds (Moore \& Wildfong, 2009; Klimova \& Leitner, 2012). This phenomenon can be used to design the new solid forms of an active pharmaceutical ingredient in order to improve physicochemical properties (Bartsch \& Griesser, 2004). Therefore, data relating to interactions between solid compounds are essential in the formation of multicomponent solid forms of active pharmaceutical ingredient (Cysewski, 2017; Yamashita, Hirakura, Yuda, \& Terada, 2014).

Ketoprofen is an ibuprofen-type drug regarded for treatment and management of pain or inflammatory caused by a condition such as dysmenorrhea, postoperative, and rheumatoid arthritis. This drug has potent pharmacological effects with low side effects (Shohin et al., 2012). However, ketoprofen is poorly water-soluble, causing its solubility to be a limiting step in the absorption process (Rençber, Karavana, \& Ozyazici, 2009). One technique to improve the solubility properties of ketoprofen is by modifying its solid forms into a multicomponent system (Perpetuo et al., 2017; Wicaksono, Setyawan, \& Siswandono, 2018). The multicomponent system of ketoprofen solid forms is carried out by combining ketoprofen with other solid components known as coformer. (Sarma, Chen, His, \& Myerson, 2011; Haneef \& Chadha, 2018). However, ketoprofen does not always create solid-state interaction with the coformer to form the required multicomponent solid forms (Cysewski, 2017; Perpetuo et al., 2017). Therefore, analysis of the solid-state interaction of ketoprofen with coformers that underlies the formation of multicomponent solid forms is fundamental in the modification of physicochemical properties of ketoprofen.

Differential scanning calorimetry (DSC) is an analytical technique for understanding the thermal properties of materials related to phase transitions (fusion, crystallization, and glass transition). DSC 
works by heating or cooling the sample as a function of time to obtain heat flow compared to references. The results of DSC can be used to describe the thermodynamic and kinetic processes of the sample quantitatively. From the DSC thermogram, the transition points of samples, such as the melting and glass transition temperatures can be determined (Zajc \& Srcic, 2004). The main advantages of DSC are the sample required for testing relatively small (2$20 \mathrm{mg}$ ), and the test can be done quickly for the whole reaction kinetics simultaneously (Trace, Khimeche, Benelmir, \& Dahmani, 2013).

Application of DSC to evaluate the solid-state interactions of drugs in the multicomponent system through thermal analysis as well as to study compatibility and stability is widely used (Wadolkowska, Winnicka, Koanik, Czyzewska, \& Miltyk, 2013). From the DSC thermogram, the possibility of interaction between components can be determined, which is marked by changes in the phase transformation, usually such as shifts in endothermic or exothermic peaks along with differences in the reaction enthalpy values (Zajc \& Srcic, 2004). DSC can also be used to analyze the solid-state interactions in binary mixtures through samples testing in several conditions so that the construction of the solid-liquid equilibrium phase diagram is obtained. The equilibrium phase diagram is a very suitable tool for analyzing the phase transitions of multicomponent systems because it can simplify complex phase diagrams of many mixtures simultaneously in one phase (Bruni et al., 2019). Thus, the solid-liquid phase diagram is an interesting and flexible method because it allows the measurement of complex phase diagrams for binary or multicomponent systems totally in one phase (Coutinho \& Meray, 1998).

Hot-stage microscopy (HSM) is an analytical technique that combines thermal and microscopy to evaluate the behavior of mixture samples due to heating and cooling treatments. The HSM shows its advantages in the analysis of solid-state interactions because it can visually identify the in-situ interactions of binary mixtures. Thus, this technique strongly supports DSC analysis when used to evaluate the solid-state interactions in the multicomponent systems. The application of HSM in the field of drug development is mostly used in conjunction with DSC to confirm interactions and thermodynamic properties of drugs in mixtures with drugs or other substances (Bakar, Nagy, \& Rielly, 2010).

The purpose of this study was to analyze the solidstate interactions of ketoprofen with coformers in binary mixtures using differential scanning calorimetry (DSC) supported by hot stage microscopy (HSM) techniques. Combined or coupled both techniques can quickly and accurately to analyze the solid-state interactions and phase transformation of solid materials in binary mixtures (Wadolkowska, Winnicka, Koanik, Czyzewska, \& Miltyk, 2013; Trache, Khimeche, Enelmir, \& Dahmani, 2013; Zhou, Chan, Sung, Tong, \& Zheng, 2016; Wicaksono, Wisudyaningsih, Widiarthi, \& Siswoyo, 2017).

The coformers used as a model for binary mixtures with ketoprofen are adipic acid and isonicotinamide. Both of these compounds are soluble in water and do not cause adverse effects on the human body thus it is often used as coformer of the multicomponent system to increase the physicochemical properties of active pharmaceutical ingredients (Ghosh \& Ali, 2012; Sowa, Slepokura, \& Jon, 2013; Yamashita, Hirakura, Yuda, \& Terada, 2014; Kerr et al., 2015; Wicaksono, Wisudyaningsih, Widiarthi, \& Siswoyo, 2017). Adipic acid is a dicarboxylic acid compound that is often used as a coformer in multicomponent systems. It has two hydrogen bond donors and four acceptor sites, so it is easy to form intermolecular interactions with other compounds. Adipic acid has been used for the modification of solid-state properties of chitosan, indomethacin, and tenoxicam (Ghosh \& Ali, 2012; Yamashita, Hirakura, Yuda, \& Terada, 2014). Isonicotinamide is the monocarboxylic acid amide derivative, which is a favored coformer in multicomponent systems. Isonicotinamide is very easy to form intermolecular interactions with other compounds because it has one hydrogen bond donor and two acceptor sites. The multicomponent system that uses isonicotinamide as a coformer is genisteine-isonicotinamide,

isonicotinamide, and atorvastatin calciumisonicotinamide. (Sowa, 2013; Kerr et al., 2015; Wicaksono, Wisudyaningsih, Widiarthi, \& Siswoyo, 2017). The molecular structures of ketoprofen, adipic acid, and isonicotinamide are shown in Figure 1.<smiles>CC(C(=O)O)c1cccc(C(=O)c2ccccc2)c1</smiles>

(a)<smiles>O=C(O)CCCCC(=O)O</smiles>

(b)<smiles>NC(=O)c1ccncc1</smiles>

(c)

Figure 1. Molecular structures of (a) ketoprofen, (b) adipic acid, and (c) isonicotinamide 


\section{EXPERIMENTAL SECTION Materials}

The materials used in this study were pharmaceutical grade ketoprofen (PT Dexa Medica, Indonesia), analytical grade adipic acid (Merck, Germany), analytical grade isonicotinamide (SigmaAldrich, USA), and analytical grade methanol (Merck, Germany).

\section{Preparation of the binary mixtures}

The powder of ketoprofen, adipic acid, and isoninicotinamide is sieved first ( 80 mesh sieve) to obtain the same size range of particles. A binary mixture of ketoprofen-adipic acid and ketoprofenisonicotinamide each made with a molar fraction of ketoprofen $0.1 ; 0.2 ; 0.3 ; 0.4 ; 0.5 ; 0.6 ; 0.7 ; 0.8 ; 0.9$ and 1.0. The components of each binary mixture are carefully mixed using a porcelain mortar and spatula to obtain the homogeneous mixtures. Each mixture is then analyzed for the phase transformation to construct the solid-liquid phase diagrams using a differential scanning calorimeter.

\section{DSC experiment}

About $2.0 \mathrm{mg}$ of sample was weighed in an aluminum container equipped with a sample lid. The sample in an aluminum container were then sealed tightly using a pressure tool. DSC test performed at the temperature range of $30-200{ }^{\circ} \mathrm{C}$ (Thermo Plus EVO II). The scanning of the sample by DSC was carried out at a heating speed of $10^{\circ} \mathrm{C} /$ minute in the dry nitrogen atmosphere. The data from DSC tests are used to construct the solid-liquid phase diagrams and to analyze the behavior of solidification of each component under both equilibrium and nonequilibrium conditions (Zajc \& Srcic, 2004; Klimova \& Leitner 2012; Benessam, Khimeche, Djellouli, Benziane, \& Dahmani, 2013).

\section{HSM experiment}

HSM experiment was conducted to analyze the interaction of solid-state ketoprofen and coformers visually. A polarized microscope (Olympus BX41) was used for the HSM experiment. In the experiment, the Scilogex MS7-H550-Pro and Olympus DP2 1 camera were used to heat the sample and to record the observation, respectively. Ketoprofen powders (about $2 \mathrm{mg}$ ) were sprinkled above a glass plate and then heated using heating equipment (Scilogex MS7H550-Pro) until the powder's meltdown. The melt was then cooled, so the ketoprofen was recrystallized. In the next step, the coformer powders are sprinkled beside the crystal of ketoprofen. The glass plate is heated again, so the ketoprofen and coformer melt together. The melt on the object-glass is then cooled, so the system solidified. Observations were made in the contact zone to examine the interactions that occur between the solid-state indicated by the existence of a new solid. The observations are documented with a camera with the appropriate magnification (Zhou, Chan, Sung, Tong, \& Zheng, 2016; Wicaksono, Wisudyaningsih, Widiarthi, \& Siswoyo, 2017).

\section{Fourier transform infrared (FTIR) analysis}

The FTIR analysis (Bruker Alpha FTIR spectrometer) was performed to confirm the interaction between ketoprofen and coformer in the solid-state. Samples for FTIR analysis were prepared by dissolving the equimolar mixture of ketoprofen and coformer in methanol. Then the solvent of the solution was evaporated at room temperature to produce dry solid. The solid is then crushed with a mortar and analyzed. The scanning by FTIR was carried out at a wavenumber $4000-600 \mathrm{~cm}^{-1}$ with a resolution of 4 $\mathrm{cm}^{-1}$.

\section{RESULTS AND DISCUSSION \\ DSC analysis}

DSC is a sufficient method to analyze the interactions between materials in the multicomponent systems. The solid-state interactions between the materials that constitute the multicomponent system can be characterized based on the phase transformation resulting from the DSC thermogram (Zaic \& Srcic, 2004). In this study, DSC testing was performed on each material and ketoprofencoformers binary mixtures. The DSC curves from the experiment are shown in Figure 2.

From the result of DSC testing, ketoprofen exhibited a sharp endothermic peak $\left(\Delta_{\text {fus }} \mathrm{H}=94.8 \mathrm{~J} / \mathrm{g}\right)$ at a temperature of $96.2{ }^{\circ} \mathrm{C}$. Adipic acid and isonicotinamide showed DSC curves with one endothermic peak at $153.8\left(\Delta_{\text {fus }} \mathrm{H}=213.4 \mathrm{~J} / \mathrm{g}\right)$ and $158.0{ }^{\circ} \mathrm{C} \quad\left(\Delta_{\text {fus }} \mathrm{H}=182.1 \mathrm{~J} / \mathrm{g}\right)$, respectively. The summary of the thermodynamic data of each material is shown in Table 1. The thermodynamic data indicated that each material has the phase transformation from solid to liquid, which indicated the melting point. The thermodynamic data from DSC experiments of ketoprofen, adipic acid, and isonicotinamide showed agreement with previous reports (Ng, Kwek, Yuen, \& Tan, 2010; Tita, D., Fulias, \& Tita, B.,, 2011 ; Yadav, Kumar, Singh, Bhat, \& Mazumder, 2013; Holanda et al., 2019). Besides, the DSC curve of each material showed only one endothermic peak indicating that the material used was stable in the test temperature range and not undergo decomposition (Trache, Khimeche, Enelmir, \& Dahmani, 2013).

The DSC curves of binary mixtures of ketoprofenadipic acid and ketoprofen-isonicotinamide have thermodynamic data, as shown in Table 2 and Table 3. The binary mixtures of ketoprofen-adipic acid and ketoprofen-isonicotinamide mostly showed DSC curves that have two endothermic peaks. The temperatures of the first endothermic peaks of the binary mixtures of ketoprofen-adipic acid (at a lower temperature) are at the temperatures range 90.9- 
92.9 ${ }^{\circ} \mathrm{C}$. In contrast, the binary mixtures of ketoprofen-isonicotinamide showed the first endothermic peaks at the temperatures range 66.3$80.4{ }^{\circ} \mathrm{C}$. The endothermic peaks of each curve at lower temperatures have almost the same value indicating the eutectic melting point of each mixture. The mixtures also have the peaks at the higher temperatures than the eutectic melting point, which indicated the melting point of the excess components in the mixtures as a function of the composition (Marinescu et al., 2015). Based on thermodynamic data from the DSC curves of ketoprofen-adipic acid and ketoprofen-isonicotinamide binary mixtures, the plotting of the molar fraction of ketoprofen versus temperature obtained the solid-liquid phase diagram (Sharma, Shakya, \& Rai, 2012).

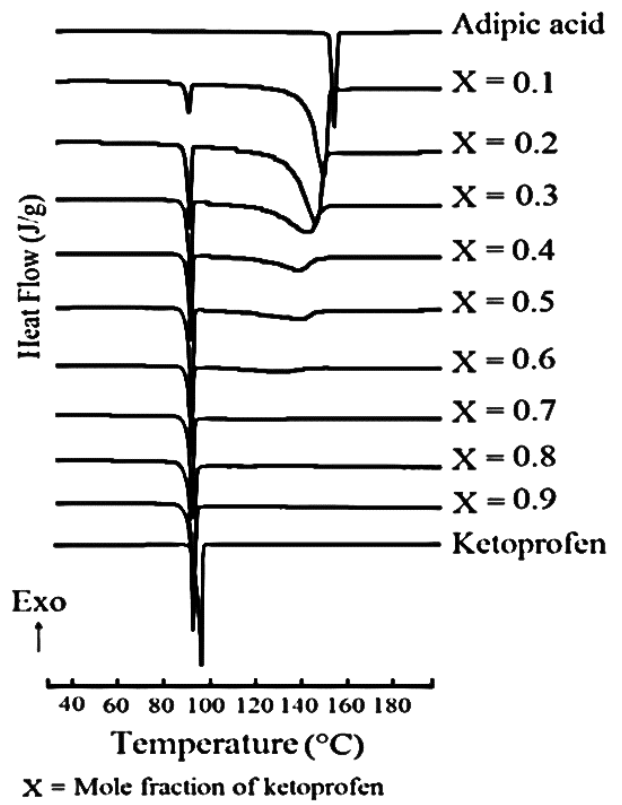

(a)

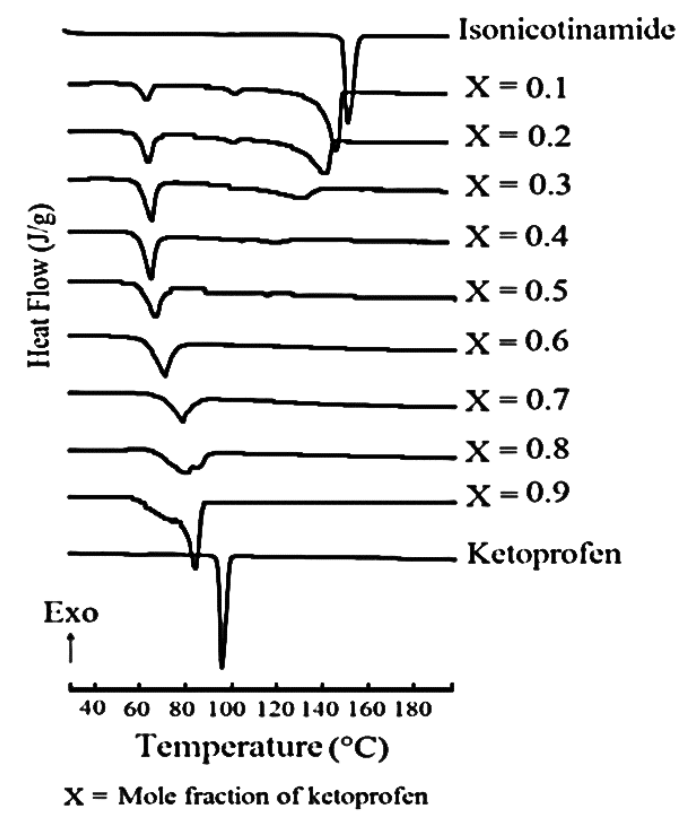

(b)

Figure 2. DSC curves of pure materials and binary mixtures

Table 1. Thermodynamic data of ketoprofen and coformers

\begin{tabular}{|c|c|c|c|c|}
\hline \multirow[t]{2}{*}{ Compounds } & \multicolumn{2}{|c|}{$\mathrm{T}_{\text {fus }}\left({ }^{\circ} \mathrm{C}\right)$} & \multicolumn{2}{|c|}{$\Delta_{\text {fus }} \mathrm{H}(\mathrm{J} / \mathrm{g})$} \\
\hline & Observation & Report & Observation & Report \\
\hline Ketoprofen & 96.2 & $96.7^{a}$ & 94.8 & $113.1^{b}$ \\
\hline Adipic acid & 153.8 & $152.4^{c}$ & 213.4 & $232.9^{c}$ \\
\hline Isonicotinamide & 158.0 & $160.0^{d}$ & 182.1 & $204.6^{d}$ \\
\hline
\end{tabular}

Table 2. Thermodynamic data from DSC experiment of ketoprofen-adipic acid binary mixtures

\begin{tabular}{cccc}
\hline $\begin{array}{c}\text { Molar fraction of } \\
\text { ketoprofen }(\mathrm{X})\end{array}$ & $\begin{array}{c}\text { pemperature } 1 \\
\left({ }^{\circ} \mathrm{C}\right)\end{array}$ & $\begin{array}{c}\Delta \mathrm{H} \\
(\mathrm{J} / \mathrm{g})\end{array}$ & $\begin{array}{c}\text { Temperature } \\
\left({ }^{\circ} \mathrm{C}\right)\end{array}$ \\
\cline { 2 - 4 } & - & - & 153.8 \\
0.0 & 90.9 & 16.8 & 149.2 \\
0.1 & 91.3 & 28.4 & 145.6 \\
0.3 & 91.6 & 45.3 & 143.4 \\
0.4 & 91.8 & 57.5 & 137.2 \\
0.5 & 92.2 & 68.7 & 140.2 \\
0.6 & 92.1 & 74.4 & 133.0 \\
0.7 & 92.1 & 86.3 & 124.4 \\
0.8 & 92.8 & 97.9 & 117.7 \\
0.9 & 92.9 & 98.4 & - \\
1.0 & - & - & 96.2 \\
\hline
\end{tabular}


Table 3. Thermodynamic data from DSC experiment of ketoprofen isonicotinamide binary mixtures

\begin{tabular}{cccc}
\hline $\begin{array}{c}\text { Molar fraction of } \\
\text { ketoprofen }(\mathrm{X})\end{array}$ & $\begin{array}{c}\text { Temperature } \\
\left({ }^{\circ} \mathrm{C}\right)\end{array}$ & $\begin{array}{c}\Delta \mathrm{H} \\
(\mathrm{J} / \mathrm{g})\end{array}$ & $\begin{array}{c}\text { pemperature } \\
\left({ }^{\circ} \mathrm{C}\right)\end{array}$ \\
\hline 0.0 & - & - & 158.0 \\
0.1 & 66.3 & 13.3 & 150.6 \\
0.2 & 67.1 & 25.7 & 145.2 \\
0.3 & 68.5 & 35.0 & 134.8 \\
0.4 & 69.2 & 56.3 & 124.1 \\
0.5 & 71.1 & 56.7 & 120.4 \\
0.6 & 73.1 & 59.0 & 113.0 \\
0.7 & 73.5 & 15.5 & - \\
0.8 & 77.2 & 19.9 & 83.2 \\
0.9 & 80.4 & 2.3 & 90.6 \\
1.0 & - & - & 96.2 \\
\hline
\end{tabular}

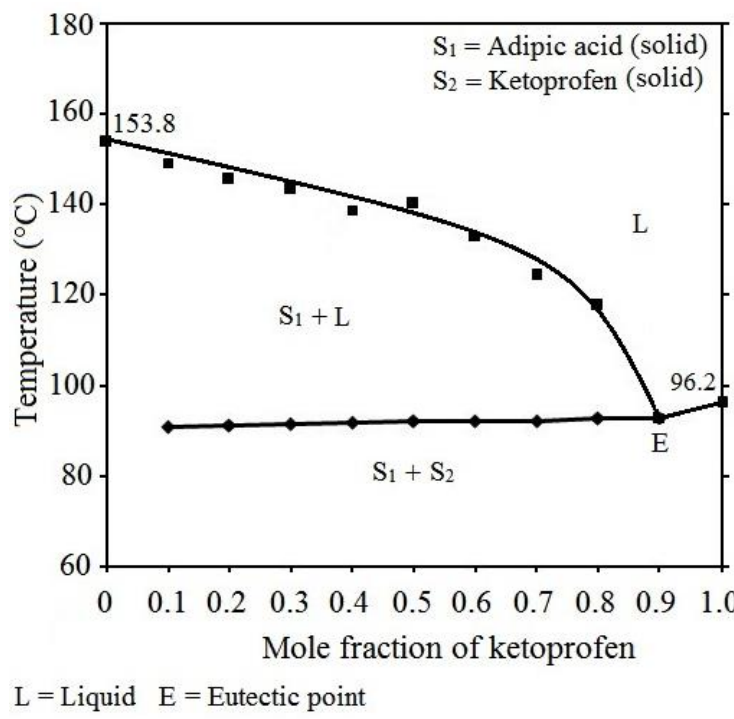

(a)

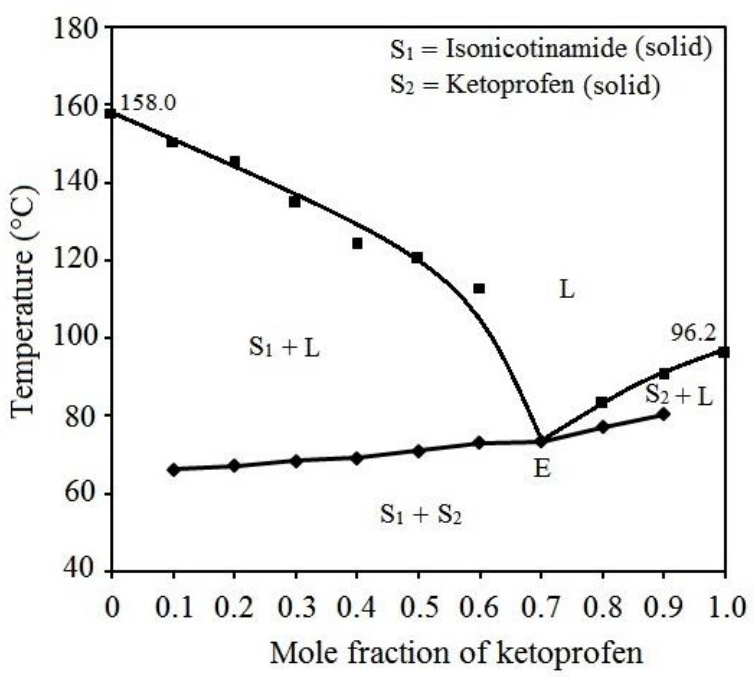

(b)

Figure 3. Solid-liquid phase diagram of binary mixtures of (a) ketoprofen-adipic acid and (b) ketoprofen-isonicotinamide systems

The solid-liquid phase diagrams of ketoprofencoformers were shown in Figure 3. At temperatures below the solid curve, the phase diagram of ketoprofen-adipic acid mixtures indicated only an immiscibility solid mixture of ketoprofen and adipic acid. At temperatures above the liquid curve, there was only a liquid phase complete miscibility mixture of ketoprofen and adipic acid. In the area between the solid and liquid curves, there was equilibrium between the solid phase and the liquid phase of the component (Sharma, Shakya, \& Rai, 2012; Rice \& Suuberg, 2010). The solid-liquid phase diagram showed that a eutectic mixture was formed from the ketoprofen-adipic acid mixture at the composition of ketoprofen molar fraction 0.9. The mixture at the eutectic composition was a miscible liquid phase of ketoprofen and adipic acid, and they would solidify at $92.9^{\circ} \mathrm{C}$.
The eutectic mixture of ketoprofen-adipic acid formed a solid microstructure with a lower melting temperature than each component. The solidification process of the eutectic composition, the components must be mutually miscible as liquids, but the solidstate of them showed immiscible. In a molecular interaction perspective, the non-bonded interaction is formed if the interaction between ketoprofen and adipic acid is higher than the interaction between similar molecules in the liquid phase. The phase diagram of ketoprofen-adipic acid has a solid-curve and a liquid-curve indicating a simple eutectic system related to the non-bonded interaction between components. A simple eutectic system of binary mixtures was indicated that the mixtures in the liquid phase were completely miscible, but in the solid phase, the mixtures were no soluble (Gorniak, Wojakowska, Karolewicz, \& Pluta, 2011; Singh \& 
Singh, 2016).

The binary mixtures of ketoprofen-isonicotinamide showed the solid-liquid phase diagram with a eutectic point in the molar fraction of ketoprofen 0.7 and a eutectic temperature at $73.5{ }^{\circ} \mathrm{C}$. The ketoprofen-isonicotinamide mixtures indicated a trend of increasing the eutectic melting point as a function of the molar fraction of ketoprofen. In the range of ketoprofen molar fraction 0.1-0.6, the eutectic temperatures were $66.3-73.1{ }^{\circ} \mathrm{C}$, while in the range of ketoprofen molar fraction 0.8-0.9; the eutectic temperatures were $77.2-80.4{ }^{\circ} \mathrm{C}$. The mixtures of ketoprofen-isonicotinamide with a molar fraction under the eutectic mixture showed a significant difference in the eutectic temperatures compared to the mixtures of ketoprofenisonicotinamide with molar fraction above the eutectic mixture. The differences in the eutectic temperatures are expected because the liquid phase of the eutectic mixture of ketoprofen-isonicotinamide interacts with excess components (Coutinho \& Meray, 1998; Cherukuvada \& Row, 2014). From the phase diagram, the liquid phase of the eutectic mixtures of the ketoprofen-isonicotinamide was indicated interacting with excess components to form the intermediate compound. The intermediate compound caused molecular rearrangement in solid-state to produces a new solid phase of a multicomponent system with different molecular networks and new eutectic point at temperature range 77.2-80.4 ${ }^{\circ} \mathrm{C}$ (Haneef \& Chadha, 2017; Cherukuvada \& Row, 2014). The new eutectic point in the mixtures of ketoprofen-isonicotinamide thought to be the cause of the formation of a eutectic system with a peritectic point in the phase diagram (Coutinho \& Meray, 1998).

\section{HSM analysis}

The hot stage microscopy (HSM) is a visual analysis used to examine the interaction between ketoprofen and coformers with treatment heating and cooling. The existence of the solid-state interactions between ketoprofen and coformers is indicated by the appearance of a new solid in the contact zone from the recrystallization process between components (Zhou, Chan, Sung, Tong, \& Zheng,
2016; Wicaksono, Wisudyaningsih, Widiarthi, \& Siswoyo, 2017). The results of the hot stage microscopy of the ketoprofen- adipic acid systems are shown in Figure 4a.

The result of the hot stage microscopy of the ketoprofen-adipic acid system indicated that ketoprofen and adipic acid during the heating process melted at temperatures around 96 and $154{ }^{\circ} \mathrm{C}$, respectively. These results showed agreement with the results from the DSC experiment. During the heating process, the ketoprofen-adipic acid system not showed morphological changes within each phase observed. On cooling, the ketoprofen-adipic acid system showed that each component solidified in the contact zone with morphological differences between the components. These results suggested that the ketoprofen and adipic acid in the mixing zone have not solid-state interactions to form a new solid phase (Zhou, Chan, Sung, Tong, \& Zheng, 2016).

Figure $4 \mathrm{~b}$ shows the hot stage microscopy of the ketoprofen-isonicotinamide systems. On the heating process, the ketoprofen showed a melting point of around $96{ }^{\circ} \mathrm{C}$, according to the ketoprofenadipic acid system. The isonicotinamide showed a melting point at a temperature of about $158{ }^{\circ} \mathrm{C}$, according to the results DSC experiment. The contact zone of the ketoprofen-isonicotinamide system has shown the solidification of the components providing a new solid which morphologically different from the individual components. The new solid in the contact zone of the ketoprofen-isonicotinamide system indicated that the each other of the components have made a solidstate interaction in the solidification process (Zhou, Chan, Sung, Tong, \& Zheng, 2016; Wicaksono, Wisudyaningsih, Widiarthi, \& Siswoyo, 2017). The solid-state interaction of the ketoprofen and isonicotinamide produced a new solid phase as a ketoprofen-isonicotinamide complex, which physically different from each primary component. The results of the hot stage microscopy of ketoprofen-adipic acid and ketoprofen-isonicotinamide systems have been shown following the results of the solid-liquid phase diagram through DSC experiments.

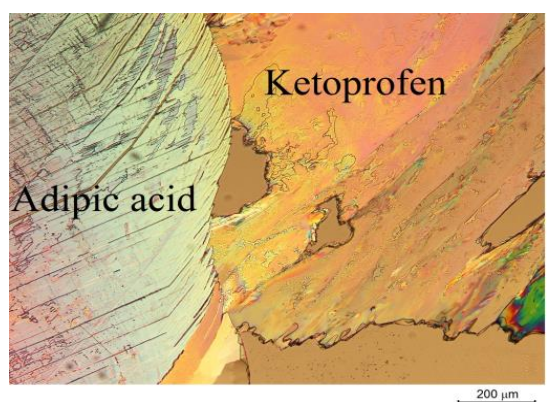

(a)

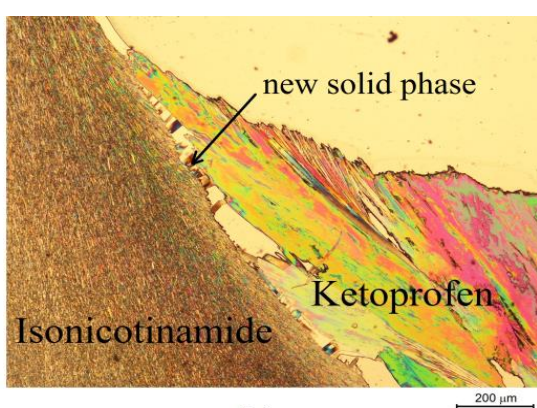

(b)

Figure 4. Hot stage microcopy of (a) ketoprofen-adipic acid and (b) ketoprofenisonicotinamide system 


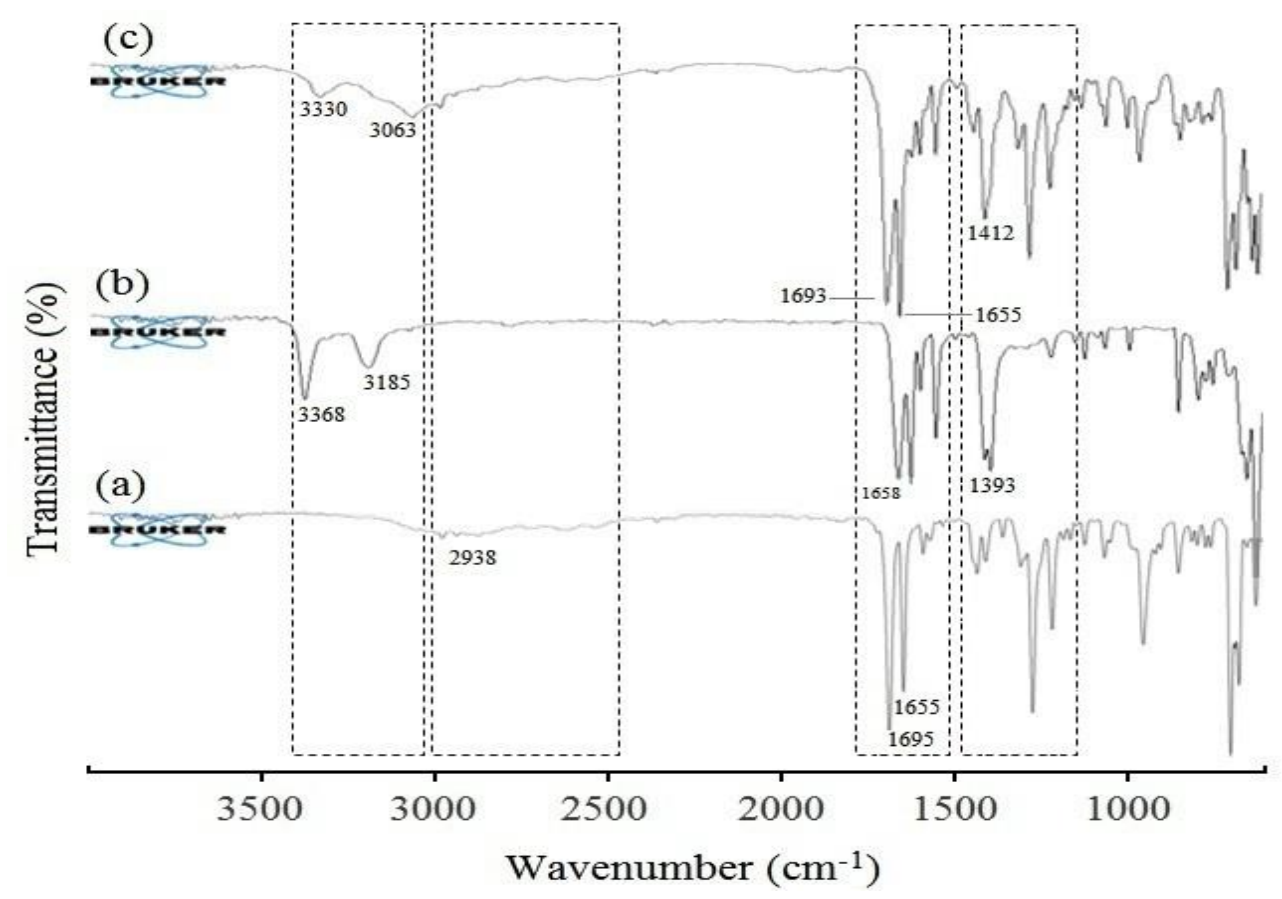

Figure 5. FTIR spectra of (a) ketoprofen, (b) isonicotinamide and (c) ketoprofen-isonicotinamide

\section{Confirmation of the solid-state interactions by FTIR}

The DSC and the hot stage microscopy experiment suggest that the components in the binary mixtures of ketoprofen-isonicotinamide form the solid-state interactions. The FTIR analysis has been carried out to confirm the presence of the solid-state interactions. FTIR spectra of ketoprofen, isonicotinamide, and ketoprofen-isonicotinamide are shown in Figure 5.

The FTIR spectra of ketoprofen have characteristic bands with the absorption peaks at $1655 \mathrm{~cm}^{-1}$ (corresponding to carbonyl $-\mathrm{C}=\mathrm{O}$ stretching), 1695 $\mathrm{cm}^{-1}$ (carboxylic $-\mathrm{C}=\mathrm{O}$ stretching), $2938 \mathrm{~cm}^{-1}$ (carboxylic - $\mathrm{OH}$ stretching) and a broad absorption peak at $3200-2500 \mathrm{~cm}^{-1}$ (group - $\mathrm{COOH}$ stretching). Isonicotinamide has a FTIR spectra with specific absorption peaks at 3368 and $3185 \mathrm{~cm}^{-1}\left(-\mathrm{NH}_{2}\right.$ stretching), $1658 \mathrm{~cm}^{-1}$ (-C=O carbonyl stretching), and $1393 \mathrm{~cm}^{-1}$ (-CN stretching). Both FTIR spectra have similarities with previous research reports (Wicaksono, Setyawan, \& Siswandono, 2018; Galvao et al., 2019). In the FTIR spectra, the absorption peaks of ketoprofen-isonicotinamide showed shifting of absorption peaks of functional groups of each material. The shifting of the functional group's absorption of the FTIR spectra indicated the intermolecular interaction between functional groups of the components of the mixtures (Wicaksono, Setyawan, \& Siswandono, 2018). Based on the functional groups involved, the intermolecular interactions are thought to be formed among others through the intermolecular hydrogen bonds. The results of the FTIR analysis have confirmed the results of the DSC and hot stage microscopy experiments.

\section{CONCLUSIONS}

The DSC experiments have shown that the solidliquid phase diagram of the ketoprofen and adipic acid in binary mixtures have a simple eutectic system. The eutectic point of ketoprofen-adipic acid mixtures showed a molar fraction of ketoprofen 0.9 with the eutectic temperature at $92.9{ }^{\circ} \mathrm{C}$. From the phase diagram indicating that mixtures of ketoprofen-adipic acid were completely miscible in the liquid phase but showed the absence of the solid-state interaction of each other in the solid phase. The ketoprofen and isonicotinamide in binary mixtures have shown a eutectic system with a peritectic point in the solidliquid phase diagram. The eutectic composition of the ketoprofen-isonicotinamide mixtures was in the molar fraction of ketoprofen 0.7 with a eutectic temperature at $73.5{ }^{\circ} \mathrm{C}$. The binary mixtures of ketoprofen and isonicotinamide have indicated that the interactions of the liquid phase of ketoprofenisonicotinamide with excess components have formed the intermediate compound. The intermediate compound has a new eutectic point at the temperature range of $77.2-80.4{ }^{\circ} \mathrm{C}$. The hot stage microscopy showed that the contact zone of the ketoprofen-adipic acid system did not show morphologically changing during the heating and cooling process. The results of the hot stage microscopy have indicated that the ketoprofen and adipic acid have not the solid-state interactions between the components. However, the contact zone of the ketoprofen and isonicotinamide has shown the formation of a new solid indicated the interaction between components. The FTIR analysis has confirmed the solid-state interactions in the ketoprofen-isonicotinamide binary mixtures. Overall, 
the DSC experiment and the hot stage microscopy have successfully identified the presence or absence of solid-state interactions in the ketoprofen-coformer binary mixtures.

\section{ACKNOWLEDGMENT}

The researcher would like to thank providing ketoprofen by PT Dexa Medica (Palembang, Indonesia) in this study.

\section{REFERENCES}

Bakar, M. R. A., Nagy, Z. K., \& Rielly, C. D. (2010). A combined approach of differential scanning calorimetry and hot-stage microscopy with image analysis in the investigation of sulfathiazole polymorphism. Journal of Thermal Analysis and Calorimetry. 99(2), 609619.

Bartsch, S. E., \& Griesser, U. J. (2004). Physicochemical properties of the binary system glibenclamide and polyethylene glycol 4000. Journal of Thermal Analysis and Calorimetry. 77(2), 555-569.

Benessam, S., Khimeche, K., Diellouli, F., Benziane, \& Dahmani, A. (2013). Phase diagram of ibuprofen with fatty acids. Journal of Thermal Analysis and Calorimetry. 112(1), 317-320.

Bruni, G., Sakai, M., Berbenni, V., Maggi, L., Friuli, V., Girella, A., \& Marini, A., (2019). Physicochemical and pharmaceutical characterization of sulindac-proglumide binary system. Journal of Thermal Analysis and Calorimetry. 136(5), 2063-2070.

Cherukuvada, S., \& Row, T. N. G. (2014). Comprehending the formation of eutectics and cocrystals in terms of design and their structural interrelationships. Crystal Growth \& Design. 14(8), 4187-4198.

Coutinho, J. A. P., \& Meray, V. R. (1998). A new method for measuring solid-liquid equilibrium phase diagrams using calorimetry. Fluid Phase Equilibria. 148, 147-160.

Cysewski, P. (2017). In silico screening of dicarboxylic acids for cocrystallization with phenylpiperazine derivatives based on both cocrystallization propensity and solubility advantage. Journal of Molecular Modeling. 23(4), 136.

Faroongsarng, D. (2016). Theoretical Aspects of Differential Scanning Calorimetry as a Tool for the Studies of Equilibrium Thermodynamics in Pharmaceutical Solid Phase Transitions. AAPS PharmSciTech. 17(3), 572-577.

Galvao, A. D., Moraes, F. T., Sousa, C. C., Sousa, K. M. D., Marchi, P. G. F., França, A. C. H., França, E. L., \& Santos, W. B. (2019). Synthesis and Characterization of a New Compound of Cobalt II with Isonicotinamide and Evaluation of the Bactericidal Potential.
Open Journal of Inorganic Chemistry. 9(2), 11 22.

Ghosh, A., \& Ali, M. A. (2012). Studies on physicochemical characteristics of chitosan derivatives with dicarboxylic acids. Journal of Materials Science. 47(3), 1196-1204.

Górniak, A., Wojakowska, A., Karolewicz, B., \& Pluta, J. (2011). Phase diagram and dissolution studies of the fenofibrate-acetylsalicylic acid system. Journal of Thermal Analysis and Calorimetry. 104(3), 1195-1200.

Haneef, J., \& Chadha, R. (2017). Drug-drug multicomponent solid forms: cocrystal, coamorphous and eutectic of three poorly soluble antihypertensive drugs using mechanochemical approach. AAPS PharmSciTech. 18(6), 2279-2290.

Haneef, J., \& Chadha, R. (2018). Antioxidant-based eutectics of irbesartan: Viable multicomponent forms for the management of hypertension. AAPS PharmSciTech. 19(3), 1191-1204.

Holanda, B. B. C., Alarcon, R. T., Gaglieri, C., Souza, A. R., Castro, R. A. E., Rosa, P. C. P., Tangerino, D. J. A., \& Bannach, G. (2019). Thermal studies, degradation kinetic, equilibrium solubility, DFT, MIR, and XRPD analyses of a new cocrystal of gemfibrozil and isonicotinamide. Journal of Thermal Analysis and Calorimetry. 136(5), 2049-2062.

Kerr, H. E., Softley, L. K., Suresh, K., Nangia, A., Hodgkinson, P., \& Evans, I. R. (2015). A furosemide-isonicotinamide cocrystal: an investigation of properties and extensive structural disorder. CrystEngComm. 17(35), 6707-6715.

Klimova, K., \& Leitner, J. (2012). DSC Study and phase diagrams calculation of binary systems of paracetamol. Thermochimica Acta. 550(0), $59-64$

Marinescu, D. C., Pincu, E., Oancea, P., Bruni, G., Marini, A., \& Meltzer, V. (2015). Solid-state study of Captopril and Metoprolol Tartrate binary system. Journal of Thermal Analysis and Calorimetry. 120(1), 829-837.

Moore, M. D., \& Wildfong, P. L. D. (2009). Aqueous solubility enhancement through engineering of binary solid composites: Pharmaceutical applications. Journal of Pharmaceutical Innovation. 4(1), 36-49.

Ng, W. K., Kwek, J. W., Yuen, A., Tan, C. L., \& Tan, R. (2010). Effect of milling on DSC thermogram of excipient adipic acid. AAPS PharmSciTech. $11(1), 159-167$.

Perpétuo, G. L., Chierice, G. O., Ferreira, L. T., Fraga-Silva, T. F. C., Venturini, J., Arruda, M. S. P., Bannach, G., \& Castro, R. A. E. (2017). A combined approach using differential scanning calorimetry with polarized light thermomicroscopy in the investigation of 
ketoprofen and nicotinamide cocrystal. Thermochimica Acta. 651(0), 1-10.

Rençber, S., Karavana, S. Y., \& Özyazici, M. (2009). Bioavailability file: Ketoprofen. FABAD Journal of Pharmaceutical Sciences. 34(4), 203-216.

Rice, J. W., \& Suuberg, E. M. (2010). Thermodynamic study of (Anthracene+ Benzo[a]pyrene) solid mixtures. Journal of Chemical Thermodynamics. 42(11), 1356-1360.

Sarma, B., Chen, J., His, H. Y., \& Myerson, A. S. (2011). Solid forms of pharmaceuticals: Polymorphs, salts and cocrystals. Korean Journal of Chemical Engineering. 28(2), 315322.

Sharma, K.P., Shakya, P. R., \& Rai, R. (2012). Solidliquid Equilibria, Physicochemical and Microstructural Studies of Binary Organic Eutectic Alloy: Urea + 2-aminobenzothiazole System. Scientific World. 10(10), 91-94.

Shayanfar, A., \& Jouyban, A. (2013). Drug-drug coamorphous systems: Characterization and physicochemical properties of coamorphous Atorvastatin with Carvedilol and Glibenclamide. Journal of Pharmaceutical Innovation. 8(4), 218-228.

Shohin, I. E., Kulinich, J. I., Ramenskaya, G. V., Abrahamsson, B., Kopp, S., Langguth, P., Polli, J. E., Shah, V. P., Groot, D. W., Barends, D. M., \& Dressman, J.B. (2012). Biowaiver monographs for immediate-release solid oral dosage forms: Ketoprofen. Journal of Pharmaceutical Sciences. 101(10), 35933603.

Singh, J., \& Singh, N. B. (2016). Phase equilibria and crystallization behaviour of Succinonitrile-8Hydroxyquinoline eutectic system. Scinzer Journal of Engineering. 2(1), 28-31.

Sowa, M., Slepokura, K., \& Matczak-Jon, E. (2013). A $1: 2$ cocrystal of genistein with isonicotinamide: crystal structure and Hirshfeld surface analysis. Acta Crystallographica Section C. 69(11), 1267-1272.

Tita, D., \& Fulias, A., Tita, B. (2011). Thermal stability of ketoprofen-active substance and tablets.
Journal of Thermal Analysis and Calorimetry. 105(2), 501-508.

Trache, D., Khimeche, K., Enelmir, R., \& Dahmani, A. (2013). DSC Measurement and prediction of phase diagrams for binary mixtures of energetic materials' stabilizers. Thermochimica Acta. 565(0), 8-16.

Wadolkowska, E. M., Winnicka, K., Koanik, A. C., Czyzewska, U., \& Miltyk, W. (2013). Application of differential scanning calorimetry in evaluation of solid-state interactions in tablets containing acetaminophen. Acta Poloniae Pharmaceutica. 70 (5), 787-793.

Wicaksono, Y., Wisudyaningsih, B., Widiarthi, F. O., \& Siswoyo, T. A. (2017). Thermodynamic and thermomicroscopy study of atorvastatin calcium-succinic acid binary mixtures. Indonesian Journal of Chemisty. 17(3), 485490.

Wicaksono, Y., Setyawan, D., \& Siswandono, S. (2018). Multicomponent crystallization of Ketoprofen-Nicotinamide for improving the solubility and dissolution rate. Chemistry Journal of Moldova. 13(2), 74-81.

Yadav, P. S., Kumar, V., Singh, U. P., Bhat, H. R., \& Mazumder, B. (2013). Physicochemical characterization and in vitro dissolution studies of solid dispersions of ketoprofen with PVP K30 and D-mannitol. Saudi Pharmaceutical Journal. $21(1), 77-84$.

Yamashita, H., Hirakura, Y., Yuda, M., \& Terada, K. (2014). Coformer screening using thermal analysis based on binary phase diagrams. Pharmaceutical Research. 31 (8), 1946-1957.

Zajc, N., \& Srcic, S. (2004). Binary melting phase diagrams of Nifedipine-peg 4000 and nifedipine-mannitol Systems. Journal of Thermal Analysis and Calorimetry. 77(2), 571 580.

Zhou, Z., Chan, H. M., Sung, H. H. Y., Tong, H. H. Y., \& Zheng, Y. (2016). Identification of new cocrystal systems with stoichiometric diversity of Salicylic Acid using thermal methods. Pharmaceutical Research. 33(4), 1030-1039. 